\title{
PATRIARCADO E CAPITAL: UMA UNIÃO LETAL PARA AS MULHERES
}

\author{
Bruna Aparecida Azevedo Gayoso' \\ Danielly Fernanda Azevedo Santos ${ }^{2}$
}

RESUMO: A persistência da violência a que as mulheres são submetidas diariamente no Brasil nos indica que este é um problema estrutural e que não se concentra no lócus das relações pessoais apenas. Existe todo um sistema complexo de relações que contribuem e se beneficiam da manutenção do status de inferioridade ao qual fomos educadas. Os corpos femininos são domesticados por uma organização entre sistema capitalista e patriarcado, de forma que todas as transgressões que fogem do que é vantajoso para este sistema é punido violentamente.

Palavras-chave: Violência, Patriarcado e Capitalismo.

\section{USO CONCEITUAL DO TERMO PATRIARCADO}

A violência tem estado continuamente em meio às preocupações mais alarmantes de toda a sociedade. Na medida em que a sociedade e os movimentos feministas questionam esta violência, ela também passa a estar na agenda do governo como um problema público. Com a intensificação das políticas neoliberais produto das necessidades de acumulação do capital em seu processo de expansão incontrolável, as contradições deste sistema tem se evidenciado, na medida em que se aprofunda a dimensão especulativa do capitalismo e se intensifica seu caráter parasitário, as classes populares, e as mulheres em particular, têm passado por um período de intensificação e precarização nos processos produtivos e de maior controle e por tanto, violência nos âmbitos do trabalho reprodutivo e na vida em geral -desemprego estrutural, violência, super-exploração, perda de direitos (que foram conquistados com intensa luta e pressão dos trabalhadores na história), miséria, fome, e a morte. Com isso a violência institucionalizada por parte do Estado também aumenta, logo que o capitalismo não aceita mais limites, nem barreiras sociais.

A violência contra as mulheres apesar de extremamente presente é de uma complexidade tal, que uma discussão aprofundada levando em conta não apenas os aspectos culturais e psicológicos, precisa ser feita. $\mathrm{Na}$ contemporaneidade temos nos deparado com notícias de ataques violentos às mulheres muito similares ou ainda mais perturbadores que os casos que ocorriam há 30, 40 ou 50 anos atrás, tudo isso com um artifício moderno que é a espetacularização, a midiatização e o julgamento das vítimas, como se fosse possível ser culpada por ser agredida.

1 Graduada em Ciências Socias pela UFGD, mestre em sociologia pelo Programa de Pós Graduação em Sociologia da UFGD, Professora da rede Estadual de Mato Grosso do Sul no município de Caarapó.

2 Graduanda do $8^{\circ}$ semestre do curso de Ciências Sociais pela Universidade Federal da Grande Dourados. 
Ao longo desta leitura ocorrerá o uso de algumas categorias que podem estar presentes no cotidiano do leitor, mas não lhe serem familiares ou claras. Portanto, cabe esclarecer alguns aspectos a respeito do uso das categorias gênero e patriarcado.

A grande crítica das estudiosas adeptas ao uso da categoria gênero com relação ao uso da categoria patriarcado refere-se ao fato de que gênero é uma categoria aberta que diz respeito à construção social do masculino e do feminino, enquanto a categoria patriarcado seria uma categoria fechada que, como o nome já evidencia, trata exclusivamente do regime de dominação/exploração das mulheres pelos homens. (SAFIOT'TI, 2004)

O que pode passar despercebido a estas críticas é que tanto patriarcado quanto gênero são categorias históricas que podem ser pensadas e utilizadas em diversas instâncias, e não só como uma categoria de análise. Neste sentido a categoria gênero, diferentemente da categoria patriarcado, não explicita alguma desigualdade. Gênero enquanto categoria de análise surge no final do século XX, quando se inicia uma busca por ferramentas conceituais que desnaturalizem a opressão feminina, então podemos falar de gênero quando tratamos a homofobia, a transfobia, a masculinidade entre outras, já o patriarcado é o conceito mais específico que trata diretamente a opressão e dominação dos homens sobre as mulheres.

É frequente ainda em meio a essas críticas, a alegação de que o patriarcado não mais existe, restando apenas resquícios do patriarcado. Com relação a isso, evidencia-se o patriarcado não se tratando somente de uma categoria analítica, mas também de um fenômeno social, que está constantemente em processo de mutação. O que significa, que nos dias atuais não encontraremos patriarcas que detêm poder de vida e morte sobre toda a sua rede familiar. Todavia, ainda hoje homens matam mulheres com uma frequência espantosa.

Além de empoderar as mulheres, o conhecimento de sua história permite a apreensão do caráter histórico do patriarcado. E é imprescindível o reforço permanente da dimensão histórica da dominação masculina para que se compreenda e se dimensione adequadamente o patriarcado. Considera-se muito simplista a alegação de a - historicidade deste conceito. Primeiro, porque esta categoria mental pode sim apreender a historicidade do patriarcado como fenômeno social. Segundo, porque na base do julgamento do conceito como a - histórico reside a negação da historicidade do próprio fato social. Isto equivale a afirmar que por trás desta crítica esconde-se a presunção de que todas as sociedades do passado remoto, do passado mais próximo e do momento atual comportaram/comportam a subordinação das mulheres aos homens. (SAFIOTTI, 2005, p.41)

Com isso, aqui recorro à categoria de análise patriarcado, considerando-a enquanto fenômeno histórico-social mutável, e endosso o pensamento de Saffioti (2015) que evidencia que o abandono da categoria patriarcado equivaleria à perda da única categoria que faz referência específica à dominação/exploração das mulheres, e que não nomeá-la é o mesmo que silenciar este processo. E acrescenta-se que quanto mais caminharmos rumo ao fim do padrão de pensamento patriarcal, mais teremos segurança em nomeá-lo enquanto patriarcado, enquanto sistema masculino de dominação/exploração das mulheres.

O patriarcado não foi naturalmente constituído, a imposição deste sistema se deu de maneira gradual e com resistência. Isso porque, nas antigas sociedades de caça e coleta, apesar de as mulheres não terem mais poder que os homens, elas eram tidas como seres místicos por dar origem 
à vide, até então não havia consciência de que esse processo ocorresse com a participação dos homens. Logo que os homens descobriram -não estamos tratando de um curto período de tempo- sua participação na antropo-produção, isso permitiu que historicamente se utilizassem deste tempo vago na caça, para imaginarem e criarem sistemas simbólicos de dominação das mulheres (SAFIOTTI, 2012, p.62-63).

Como somos direcionados ao pensamento dicotômico, por vezes, alguns críticos à existência do patriarcado o questionam sob a desculpa de que não há registro de matriarcado, logo, sob esta lógica, não poderia haver um patriarcado.

Neste erro, aliás, não incorrem apenas as pessoas comuns. Feministas radicais também procederam desta forma. De acordo com a lógica dualista, se há patriarcado, deve haver matriarcado. A pergunta cabível naquele momento e ainda hoje é: houve sociedades com igualdade social entre homens e mulheres? Esta interrogação teria, muito seguramente, dado outro destino à valorização da importância do conceito de patriarcado na descrição e na explicação da inferioridade social das mulheres. (SAFIOTTI,2005 p.39)

Segundo as evidencias encontradas por Lerner apud Saffiotti (2005), o patriarcado conta com aproximadamente 2.400 anos de vigência, se somarmos desde o início de seu processo de instauração temos quase cinco milênios de dominação masculina - isso não significa que não houve ou que não há resistência a este sistema por parte das mulheres.

A propósito disto, cabe lembrar uma bem plausível e pertinente hipótese de Lerner, que, seguramente, foi uma precondição do estabelecimento da supremacia masculina. Enquanto a coleta constitui atividade cotidiana, ocupando, portanto, o tempo das mulheres ao lado de outras tarefas, inclusive maternagem, a caça ocorre uma ou duas vezes por semana, deixando tempo livre aos homens. O exercício da criatividade exige tempo livre, e os homens, certamente, o usaram para criar sistemas simbólicos que inferiorizaram as mulheres, como também forneciam os elementos para a interpretação do cotidiano no sentido da constituição de sua primazia. De posse, além do mais como autores, dos esquemas de interpretação da realidade, foi, com certeza, fácil, para os homens, estabelecer seu domínio sobre as mulheres. (SAFFIOTI, 2005, p. 55).

Com isso, ressaltamos que em face da história da humanidade o patriarcado é bastante recente, ou seja, nem sempre a humanidade funcionou sob um sistema hierárquico de controle das mulheres e dos filhos. Com isso ressalta-se que neste período mãe e prole funcionavam como uma unidade, já que a mãe amamentava a criança ela precisa carregá-la para todo lado. Sendo assim não poderia se ocupar da caça que requer o máximo silêncio. A caça ficava atribuída aos homens, o que consequentemente os deixava com muito tempo ocioso para confabular (SAFIOTTTI, p.127, 2005).

O patriarcado -assim como o capital- se solidifica, se corporifica e se utiliza de tudo à sua volta para manter o status quo, inclusive do gênero, considerando que gênero se refere às formas de construção do masculino e feminino. Esta construção social passa pelo cunho do patriarcado quando defende/impõe características e tipos de comportamentos que são considerados superiores a homens e inferiores a mulheres.

Nesta busca constante por enquadrar homens e mulheres em "estereótipos padronizados", as formas de se constituir social e sexualmente passam pelo crivo do poder e da opressão, 
marginalizando grupos e condicionando-os à violência. Esta conjectura é ainda mais complexa com relação às maneiras de ser ou de se construir mulher. Apesar das subjetividades e especificidades de cada indivíduo, na sociedade patriarcal e capitalista, os indivíduos são categorizados, classificados e estereotipados a partir de uma lógica hierárquica e perversa para manutenção do sistema como um todo, e essa hierarquia é muito mais intensa com relação às mulheres.

O modo como a história das mulheres se entrecruza com a história do desenvolvimento capitalista não pode ser compreendida se nos preocuparmos apenas com os terrenos clássicos da luta de classes -serviços laborais, índices salariais, rendas e dízimos- e ignorarmos as novas visões da vida social e da transformação das relações de gênero que tais conflitos produziram. (FEDERICI, 2017, p.44)

Com isso, ressalta-se que é necessário compreender a desigualdade de gênero à luz da luta de classes, e a luta de classes a partir das especificidades da questão da mulher. É fato que o poder permeia as relações de gênero. Todavia, esse poder poderia ser partilhado, mas ele é exercido de maneira a criar desigualdades, o que acarreta uma divisão entre explorados/oprimidos/subalternizados e quem oprime/explora/subalterniza e impede a emancipação das mulheres, e retira delas seu poder de decidir sobre seus corpos e sobre seus destinos. É importante evidenciar que a existência de uma classe que é subordinada a outra, significa que o patriarcado e o capital atribuíram forçosamente este padrão de comportamento, mas que sempre que possível, a partir dos meios disponíveis, qualquer grupo submetido a esta exploração tentará minar a exploração advinda do outro grupo.

O fato de o patriarcado ser um pacto entre os homens não significa que a ele as mulheres não oponham resistência. Como já se patenteou, sempre que há relações de dominação-exploração, há resistência, há luta, há conflitos, que se expressam pela vingança, pela sabotagem, pelo boicote. (SAFIOTTI, 2005, p.64)

Partindo disso, critíco e abandono veementemente todo e qualquer discurso que parta do pressuposto de que as mulheres são submissas por não terem iniciativa para romper com este padrão ou que a classe trabalhadora se encontra em situação de exploração porque é alheia a sua situação e não tem consciência de que é explorada. Muito pelo contrário, o que temos visto cotidianamente em todos os espaços da vida coletiva é que as mulheres tem estado cada vez mais atentada e se posicionado contra os desmandos de todos os órgãos que tentam manter a opressão e submissão das mulheres.

\section{A REDINAMIZAÇÃO DO PATRIARCADO PELO CAPITAL}

Quando o capitalismo se consolidou como o sistema social-político-econômico, o patriarcado já era pujante na sociedade. E como o capitalismo é um sistema de controle que se utiliza de todas as ferramentas disponíveis para maximizar seu poder, o patriarcado é redinamizado e se configura como um instrumento imprescindível em sua caixinha de ferramentas para manutenção das hierarquias necessárias à reprodução do sistema.

É fato então, que o capitalismo reproduz condições extremamente adversas à mulher, uma vez que revitaliza o patriarcado. Junto ao processo de individualização instaurado pelo capitalismo, a mulher é inserida numa desvantagem dupla: o patriarcado em sua longevidade se comparado ao 
capitalismo, já havia instaurado uma desvalorização das capacidades femininas, e usando esta lógica o capitalismo marginaliza as mulheres das funções produtivas (SAFIOTTI, 1976).

No livro o Calibã e a Bruxa (2017), Silvia Federici examina a acumulação capitalista do ponto de vista das mudanças que a mesma introduziu na posição social das mulheres e na produção de força de trabalho. Com isso, a autora acrescenta à discussão iniciada por Marx, uma série de fenômenos que também foram extremamente importantes para a acumulação capitalista, como:

I) o desenvolvimento de uma nova divisão sexual do trabalho;

II) a construção de uma nova ordem patriarcal, baseada na exclusão das mulheres do trabalho assalariado e em subordinação aos homens; III) a mecanização do corpo proletário e sua transformação, no caso das mulheres, em uma máquina de produção de novos trabalhadores. (FEDERICI, p.26, 2017)

Com isso, evidencia-se que o patriarcado apesar de existir há muito mais tempo que o capitalismo, é usado e redimensionado pelo mesmo, de maneira que as relações sociais são complexificadas e transformadas de acordo com a necessidade do sistema capitalista, de forma que as mulheres são vistas pelo sistema como um útero, que tem a possibilidade de "criar" mão de obra, e este trabalho de reprodução é o pano de fundo da posição social das mulheres.

O capitalismo marginaliza e explora o trabalho das mulheres, não só o trabalho produtivo como também o reprodutivo, Melliassoux se questiona:

¿Cometió Engels un error al colocar en el mismo plano la producción de los medios de existencia y la producción de los hombres? Así lo considera la nota de la redacción en la edición publicada por las Ediciones Sociales, según la cual esta asimilación sería una «inexactitud». Es una solución fácil de una producción esencial entre todas, la de energía humana, o, en el sistema capitalista, la de fuerza de trabajo. La reproducción de los hombres es, en el plano económico, la reproducción de la fuerza de trabajo en todas sus formas. Pero el materialismo histórico, del cual se podría esperar que concediera una mayor importancia a este tema, y aun cuando haya sido el único en plantear el problema, sólo integra imperfectamente la reproducción de la fuerza de trabajo en su análisis. (MELLIASSOUX, 1975, p.03)

Claude Melliassoux faz uma indagação muito coerente, já que para além da opressão que o patriarcado impõe às mulheres, com o capitalismo passamos a ser exploradas, tendo nossa energia vital alienada através da exploração do trabalho produtivo e reprodutivo. De todas as necessidades que o capitalismo tem, a reprodução da vida humana (é a única que ele não produz por si só, com isso, a exploração das mulheres se funda no trabalho reprodutivo não remunerado.

Numa sociedade em que a estrutura de classes subordina todas as demais relações, em que o capitalismo condiciona o poder à burguesia, consequentemente a sexualidade e as relações de gênero também são permeadas por estas condições estruturantes de estratificação e subordinação de algumas classes. É evidente que as questões de classe não estão acima de todas as outras, mas esta sempre está relacionada aos demais problemas sociais, já que os problemas de classe são fundantes e condicionam os outros microcosmos. Sendo assim para falarmos de sexualidade, poder e violência, é comum a necessidade de visitarmos as questões da luta de classes capitalista.

Cabe dizer que o patriarcado não nasce com o capitalismo. Todavia o capitalismo incorpora o 
patriarcado e o intensifica a um ponto máximo, tornando-o ainda mais complexo e violento. Com isso, é possível ver com clareza cada vez maior a corporificação do patriarcado. Para além de uma categoria de análise, o patriarcado é um fato social que atinge materialmente os corpos e as vidas das pessoas.

O capitalismo é de fato um sistema de opressão/exploração/dominação, e que sua razão de ser é a maximização do lucro, a expansão e a dominação, ele se beneficia das desigualdades que ele mesmo cria em relação às classes sociais e aos grupos heterogêneos. Então de maneira geral toda a classe trabalhadora é superexplorada e oprimida. Nestas circunstancias, o capitalismo também se utiliza do patriarcado como instrumento de manutenção da exploração das mulheres.

Todavia, é interessante perceber que a exclusão da mulher da sociedade capitalista não é vantajosa para o capital, isso porque o sistema capitalista se utiliza da mulher ora no mercado de trabalho, ora reintegrando-a ao espaço doméstico de maneira controlada e disciplinada. Sendo assim, a própria inserção da mulher no mercado de trabalho é contraditória. Isso porque ao mesmo tempo em que sair do espaço casa/lar e alcançar a vida pública é de fato uma conquista que auxilia ao rompimento dos estereótipos que vinculam a mulher aos padrões de domesticidade e maternidade, esta inserção não ocorre de forma a romper com os padrões estabelecidos, seja no mercado de trabalho ou na esfera da política.

$\mathrm{Na}$ realidade a própria inserção das mulheres no mercado de trabalho ocorre por interesse do capital, isso porque, uma das formas de aumentar a taxa de lucro é baixar o valor pago pela mão de obra, e o sistema capitalista pode rebaixar em até 30\% o salário das mulheres (em funções em que as mulheres têm maior aptidão física) frente ao salário dos homens, principalmente em países de capitalismo dependente. Aqui pensamos que como o capitalismo é o processo em que um valor se valoriza, a intenção final é a obtenção da mais-valia, e isso pode ser maximizado com a compra de uma força de trabalho que seja mais barata

Enquanto o capitalismo precisa inserir a mulher no mercado de trabalho e no mercado de consumo também, ele precisa (para manter a taxa de mais- valia) que estas mulheres sejam desvalorizadas, num sentido de se minimizar o valor de seu trabalho e suas atividades. A partir disso o capitalismo se reproduz como um sistema desigual e impede a emancipação da mulher, e a emancipação humana como um todo.

O atual cenário de desigualdades tão intensas é um reflexo do uso que o capitalismo faz de outras subestruturas com o mesmo interesse de criar desigualdades a partir das diferenças, resultando na criação de subclasses dentro da classe trabalhadora. Exemplo disto é a existência de uma estrutura de poder que unificas as três ordens: classe, raça/etnia e gênero. Essa relação Saffioti chamou de nó teórico:

O difícil é lidar com o nó formado pelas três subestruturas: gênero, classe, raça/etnia. Uma voz menos grave ou mesmo aguda de uma mulher pode não ser relevante em sua atuação segundo o preconceito étnico-racial, mas o é, seguramente, na relação de gênero e, até certo ponto, na de classes. O importante é analisar estas contradições na condição de fundidas ou enoveladas ou enlaçadas em um nó. Não se trata da figura do nó apertado, mas do nó frouxo, deixando mobilidade para cada uma de suas componentes (SAFFIOTI, 1998, p.59).

Desta forma, as relações de gênero, de classe, raça/etnia são enoveladas no sistema capitalista, de forma que a solução dos conflitos inerentes a estes âmbitos particulares torna-se impossíveis. Em alguns momentos históricos do desenvolvimento capitalista, a discussão das questões relacionadas 
a emancipação e autonomia da mulher pode e é ativada, mas esta discussão é limitada as possibilidades de manutenção do sistema.

Segundo Mészáros apud Cisne: "Durante o desenvolvimento histórico do capital também são ativadas algumas potencialidades positivas para a emancipação das mulheres apenas para serem mais uma vez anuladas sob o peso das contradições do sistema" (MÉSZÁROS apud CISNE, p.120, 2012). Desta forma, a violência contra as mulheres somada a diversos outros problemas sociais são na verdade sintomas da crise estrutural do capital, não é então o problema em si, mas sim, sintomas de um problema maior que é uma crise profunda que deixou de cíclica e que foi gerada pelo próprio sistema, e que caminha possivelmente para uma implosão.

Existe uma discussão sobre os caminhos que o sistema capitalista precisaria percorrer para chegar ao seu fim, se seria uma autodestruição ou uma destruição externa. É possível que o próprio sistema esteja produzindo os males que levarão ao seu fim, ainda assim é importante que a classe trabalhadora e os movimentos socias ajam no sentido de findar as opressões do sistema capitalista e patriarcal.

\section{CONSIDERAÇÕES FINAIS}

A desigualdade oriunda do capitalismo através da alienação do trabalho culmina na consubstancialidade ${ }^{3}$ de todas as outras relações de poder e desigualdades, sejam elas de raça/etnia, gênero, nacionalidade e outras. Na mesma medida em que não há meios de alcançar a emancipação das mulheres sem ter alcançado também a emancipação do capitalismo, não há como buscar romper com a lógica do capital sem questionar o patriarcado e relações desiguais de raça/etnia, classe e gênero.

Importante, no entanto, esclarecer que a luta contra as desigualdades de gênero e contra a violência doméstica pode ocorrer ainda nesse contexto do sistema capitalista, o foco principal deve ser o rompimento do sistema de opressão como um todo, mas não podemos incorrer no erro de acreditar que só podemos alcançar os benefícios do fim do patriarcado quando alcançarmos o fim a queda do sistema capitalista. As reformas que são feitas dentro deste sistema precisam ser consideradas e almejadas, só não podem trazer consigo um contentamento e um sentimento de satisfação que nos distancie da derrubada plena do sistema de opressão e exploração das mulheres e da classe trabalhadora como um todo.

\section{REFERÊNCIAS}

FEDERICI, SILVIA. (2017) Calibã e a Bruxa: Mulheres, Corpo e Acumulação Primitiva. Tradução de Coletivo Sycorax, São Paulo,Elefante.

MELIASSOX, Claude. (1975) Mujeres, graneros y capitales: Economía doméstica y capitalitales. Traducción: Oscar del Barco, Siglo Veintiuno Editores Mexico.

SAFFIOTI, Heleieth I.(2004) B. Gênero, patriarcado, violência. São Paulo: Editora Fundação Perseu Abramo.

3 Aqui não é necessário elaborar uma discussão a respeito dos conceitos de interseccionalidade e consubstancialidade, para isso indico HIRATA, Helena. Gênero, classe e raça Interseccionalidade e consubstancialidade das relações sociais. 2014. 
SAFFIOTI, Heleieth. Gênero e Patriarcado: a necessidade da violência.(2005) In: MARTÍN,Marcia;

OLIVEIRA,Suely. (org.)Marcadas a Ferro: violência contra a mulher uma visão interdisciplinar, Brasília: Secretaria Especial de Políticas para Mulheres. 